\title{
Evaluation of HIV counselling and testing, self-disclosure, social support and sexual behaviour change among a rural sample of HIV reactive patients in South Africa
}

\author{
E Sethosa, Health Behaviour Research Unit, University of the North \\ $K$ Peltzer, University of Venda for Science and Technology \& Human Sciences \\ Research Council
}

\begin{abstract}
The aim of this study was to evaluate HIV counselling and testing, self-disclosure, social support and sexual behaviour change among HIV reactive patients among a rural sample of HIV reactive patients in South Africa. The sample consisted at the post-test counselling exit interview of 55 participants (41 women and 14 men) who tested HIV-positive conveniently selected from a rural hospital and at five months follow-up at their homes 47 . Results indicated that most patients had an HIV test because of medical reasons. At follow-up only $36 \%$ had disclosed their HIV status and half of the participants had had sex without condoms in the past three weeks. Major reason for not disclosing of their HIV status were being afraid of negative reactions, fear of discrimination, fear of violence, concerns about confidentiality and not yet ready. Social support was found to be significantly related to disclosure of HIV status, while counselling context and content and counselling satisfaction were not related with HIV disclosure.
\end{abstract}

\section{Introduction}

The primary objectives of HIV Voluntary Counselling and Testing (VCT) services are (1) to provide an opportunity for persons to learn their HIV sero-status and if infected, to obtain referrals for medical and psychosocial care and (2) to provide counselling so that clients might change their behaviour to avoid infection or, if they are already infected, to avoid transmitting the virus to others (Centers for Disease Control, 2001: 2f.).

As much as there are barriers to HIV counselling and testing, there is also compelling evidence that suggest the advantages of providing these services as part of a comprehensive HIV and STD prevention programme in the developing world (Campbell; Marum; Alwano-Edyegu; Dillon; Moore, \& Gumisiriza, 1997: 92).

According to Campbell et al. (1997: 93), there is growing evidence that HIV counselling and testing in developing countries can help empower individuals and couples to adopt safer behaviours. A study of discordant couples where one member is HIV positive and the other HIV negative in Rwanda found that confidential HIV testing with counselling caused a large reported increase in condom use and was associated with lower rate of new infections among couples (Allen; Tice; Van De Perre; Serufilira; Hudes; Nsengumureyi; Bogaerts; Lindan, \& Hulley, 1992: 1605). Müller, Sarangibin, Ruxgungtham, Sittitrai and Phanuphak (1995) studied the relationship between HIV counselling and testing and sexual risk behaviour in HIV seropositive patients in Thailand. They had a control group who answered the questionnaire before HIV VCT and the study group who answered the questionnaire after HIV VCT and found out that most study group patients reported a marked decrease in their sexual activity and in their number of sexual partners after HIV VCT and consequent knowledge of positive HIV serostatus. They also reported lower numbers of sexual partners and higher condom use rate than the control patients. Sangiwa, Van der Straten and Grinstead (2000: 35) asked Tanzanian participants in a qualitative interview to describe how they felt VCT played a role in prevention, both in general and in their own personal experience. Participants reported that VCT played a role in a number of ways. First, VCT increased awareness and knowledge of preventive and care measures both for self and for others. 
Second, VCT was described as a "wake-up" call among some HIV-seronegative clients, increasing their perceived vulnerability to HIV and thus promoting caution. Third, VCT promoted behavioural change. Participants also described factors influencing behaviour change including how gender and HIV serostatus intersected and shaped their choice of risk reduction strategies and beliefs and attitudes that may interfere with enacting intentions to change.

For counselling to be effective, it has to be client-centred. This model of HIV counselling was designed to decrease the emphasis on counselling on providing information and to focus instead on understanding the client's unique risk behaviour and the context in which that behaviour occurs. According to the Centers of Disease Control (1999: 3-5), client-centred HIV prevention counselling is an interactive risk-reduction model which is usually conducted with HIV testing, in which the counsellor helps the client identify and acknowledge personal HIV risk behaviours and commit to a single, achievable behaviour change step that could reduce the client's HIV risk. The goal of client-centred counselling is to conduct an individualized risk assessment, which may or may not include HIV antibody testing and to develop an effective individualized risk reduction plan (Grinstead, 1997: 125). This model was reported to be effective in reducing high-risk sexual behaviours and new Sexually Transmitted Diseases (STDs) (Kamb, Fishbein \& Douglas, 1998: 1161), was feasible to use even in busy publicly funded clinics and acceptable to clients, counsellors, and health-care providers (Kamb et al., 1996: 99); and was cost effective at preventing STDs in persons at increased risk of HIV (Holtgrave, Reiser \& DiFranceisco, 1997: 105).

\section{Self-disclosure of HIV status}

Disclosure of HIV serostatus has been conceptualised as a reasoned action following subjective evaluation of the various consequences of informing others (Marks; Bundek; Richardson; Ruiz; Moldonado, \& Mason, 1992: 302). Marks, Richardson and Maldonado (1991: 1321) indicate that individuals who are aware that they are infected with HIV and who engage in sexual relations have a social and legal responsibility to disclose their infection to their partners. Withholding this information increases the potential for HIV transmission because it creates a situation in which unsafe sexual activity is more likely to occur. Should a partner become infected, he or she may unknowingly infect others. This chain of events suggests that non-disclosure of HIV infection to sexual partners may be an important cause of the continuing HIV epidemic. Factors that influence the decision to disclose may vary from situation to situation so that individuals may disclose to all, some or none, depending on factors involved in their decision-making process (Moneyham et al., 1996: 209).

Practical and psychological difficulties of disclosure exist for sexually active individuals living with HIV. Decisions about disclosure of HIV status involve anxiety, stigma and shame. Divulging to sexual partners may lead to isolation or even physical injury. Stein; Freedberg; Sullivan; Savetsky; Levenson; Hingson, R \& Samet, (1998: 253) indicates that there are powerful forces working against disclosure. First, there are psychological consequences of dis- closure, especially the risk of rejection. Second, there are practical social ramifications, desired sexual encounters may be missed, and financial or sick care support may be denied. Third, HIV infected individuals may rationalize that their partners need to protect themselves, thus, protection is every individual's responsibility.

For infected individuals, sexual choices after testing may become life and death choices. The need to change deeprooted sexual behaviours, to say "no" to risky sex or use condoms, to refrain from certain types of sex, all have to be negotiated. Partners have to be engaged in these negotiations. For many women, this is either a new experience or one that lies outside of culturally dictated behaviour (Worth \& Rodriquez, 1987: 5). In cultures in which it is not the norm to discuss sex or intimacy, women who do attempt to control their sexuality are perceived as deviating from the cultural ideal. This makes it difficult for women to initiate safe sex negotiations, to realise that she is going to have to participate in making the rules (Hammond, 1987: 29).

Non-disclosure of HIV serostatus has its own risks. Concealment of HIV status may be stressful, and the pain of deception and putting others at risk may feel isolating. Nondisclosure removes people who may offer social support, which has been noted to lessen the effect of physical symp toms on depression (Hays, Turner \& Coates, 1992: 463).

There is considerable evidence that individuals cope better with stressful events (such as living with HIV) if they have someone with whom to discuss their personal difficulties (Lane \& Wagner, 1995: 237). For instance, Remien, Rabkin, Williams and Kattof (1992: 301) found that having a confidant (someone around to confide in or talk to about yourself and your problems if you want to) was positively associated with psychological coping among persons who were long-term survivors of AIDS. Maman, Mbwambo, Hogan, Kilonzo and Sweat (2001: 602) found in a Tanzanian adult sample that the primary perceived barrier to HIV serostatus disclosure among women was fear of partners' reaction. Sliep, Poggenpoel and Gmeiner (2001: 56) also found the fear of being rejected because of one's HIV status as a major barrier to self-disclosure among HIV reactive patients in rural Malawi. A study examining the effects of maternal HIV infection on pregnancy outcomes in Kenya reported increased violence and loss of security for some of the women involved who shared information about their HIV seropositivity with others (Temmerman, Ndiya-Achola \& Piot, 1995: 969). Campbell et al. (1997: 104) found that although most women did not share serostatus information with their partners, those who did were either replaced by another wife, some were beaten, and others committed suicide. Women in this context are often blamed for bringing AIDS into the family and the options for these seropositive women are to cope with their unfair burden silently or share serostatus information with their partners and risk violence or divorce.

Maman; Mbwambo; Hogan; Kilonzo, \& Sweat, (2001: 596) points out the low HIV status disclosure rate to sexual partners among clients who have been counselled and tested for HIV in Tanzania, e.g. from 708 female VCT clients only $27 \%$. 


\section{Social support}

Duffy and Wong (1996: 56f.) define social support as an exchange of resources between two individuals perceived by the provider or recipient to be intended to enhance the well being of the recipient. Three conceptualisations of social support are distinguished by Pierce, Sarason and Sarason (1990: 73), they are social network or structural approach, the social support as helping or as functional support and the general perception approach.

Learning that one is HIV sero-positive can create a number of stressors. The person might be concerned about dying at an early age, the pain and suffering associated with a debilitating and ultimately fatal illness, being stigmatised as an HIV or AIDS patient or disruption in relationships with friends and family (Derlega \& Barbee, 1998: 20f.). One coping strategy that people use is seeking social support. Care and support for people who are HIV positive should play a critical role in assisting them to understand the need for prevention and to enable them to protect others. Social support has been shown to lead to lasting changes in behaviour. Studies, mainly from developed countries, suggest that care and support in the form of ongoing counselling for HIV positive individuals and discordant couples can play a major role in preventive behaviour (MacNeil, Mberesero, \& Kilonzo, 1999: 537). Kline and Van Landingham (1994: 319) examined frequency of consistent condom use in 214 HIV infected women over a four-week period. They found that when care and support were weak for infected women, they tended not to reveal their HIV status to their partners.

\section{VCT and sexual behaviour change \\ Sexual behaviour change}

Changing or modifying sexual behaviour is a complex process with individual, emotional, societal, practical and economic aspects. The expectation that VCT, comprising one pre- and one post-test counselling session, will always result in safe sexual behaviour is often unrealistic. Difficulties may be compounded if people are tested alone and feel unable to share their test result with the partners. There are different things that can make a change of risk behaviours difficult. They are communication difficulties, gender imbalances, desire to have children, and economic deprivation (UNAIDS, 2001: I1f.).

Women are often unable to discuss safer sex with their husbands or sexual partners following counselling and testing because of gender imbalances in sexual decision-making. This seems to be a particular problem for married women, who depend on their husbands for food and security, and sex workers. In a study conducted by Karim (1995: 1521 ), it was noted that women need communication and negotiation skills so that they can discuss sexual and other issues with their partners. A study from $R$ wanda found that men control sexual decision-making and seropositive women were more likely to report coercive sex with their partners (Van der Straten, 1995: 935).
If a woman was able to discuss her HIV status, or her husband had previously been tested, she was in a much better position to discuss or attempt negotiating for safer sex and condom use was higher. Participation of the male partner is crucial for successful HIV risk reduction in couples (UNAIDS, 2001: 32f.). In Zimbabwe, according to Meursing and Sibindi (1995: 56), women also reported that it was difficult to make changes in sexual behaviour due to their lack of power in sexual situations. Even if women were able to share their seropositive status with their sexual partners, they were often unable to insist or even discuss condom use. Men stated that they did not like condoms and they were not thought to be appropriate within marriage. Weinhardt, Carey, Johnson and Bickham (1999: 1397) reviewed that HIV counselling and testing appears to provide an effective means of secondary prevention for HIVpositive individuals.

Thus, the aim of this study was to evaluate HIV counselling and testing, self-disclosure, social support and sexual behaviour change among $\mathrm{HIV}$ reactive patients among a rural sample of HIV reactive patients in South Africa.

\section{Methods \\ Sample and procedure}

At the post-test counselling exit interview the sample consisted of 55 participants ( 41 women and 14 men) who tested HIV-positive (reactive to both ELISA and Orgenics). Their ages ranged from $18-59$ years, with an average of 27.9 years $(\mathrm{SD}=8.2$ ). Most were by ethnicity Nothern Sotho $(49,89 \%)$, and $6(11 \%)$ were Tsonga, Ndebele or Zulu. Almost twothirds $(34,62 \%)$ were single, separated, widowed or divorced, and $21(38 \%)$ were married or lived with a partner. The majority $(49,89 \%)$ lived in rural areas and $6(12 \%)$ lived in an urban area. From the 55 participants 47 could be followed-up, three had passed away, one was too sick to be interviewed and four could not be found after three repeated visits, as they had gone to seek for treatment elsewhere.

Participants were conveniently selected for participation in the study as they presented for post-test HIV counselling at Mankweng hospital outpatient Health Information Centre. The researcher (E.S.) conducted an exit interview after informed consent was taken. Patients were assured of confidentiality and anonymity. Only one participant opted not to participate. A questionnaire with open and close-ended questions was interview-administered by the first author (ES). Open-ended responses were written down immediately after the interview. After the exit interview patients were followed-up for a second interview at their homes, in privacy, after five months. Some of the interviews were very emotional especially where the person was already symptomatic but could walk properly. Many of them had not yet disclosed their status to anybody and had no one to talk to about their problems, and when the researcher showed up they were very happy to talk about their condition. The researcher referred those who were not coping all right emotionally, and in terms of food to the hospital for further counselling and to the social workers for food packages for 
the children. All the participants accepted the researcher and they were very much at ease with her.

The research protocol was approved by the human ethics research committee of the University of the North, the Department of Health and Welfare of the Limpopo Province and the superintendent of Mankweng Hospital.

\section{Measures}

Measures at first interview included socio-demographic data, reasons for HIV testing, HIV General and Transmission Knowledge, Counselling Content and Context, Counselling Satisfaction, and past sexual risk behaviour (number of partners, history of STD, rape, condom use), and measures at follow-up interview included HIV General and Transmission Knowledge, Self-disclosure (including open-ended question: "Why did you tell or didn't tell this person of your HIV status?"), Social Support, General Health, Behaviour change (including open-ended question: "Why did you use or not used condoms in the past three weeks when you had vaginal sex?").

A 20-item on HIV-related Knowledge and Transmission $\underline{\text { Scale }}$ was used. The questions were developed through consultation with experts in the HIV field and through literature review (Carey \& Schroder, 2002: 172). The first nine knowledge questions were rated on a three-point scale from true, false, to not sure, and the last eleven transmission knowledge questions were rated on a six-point scale, rated from $1=$ very likely to $6=$ definitely not possible. The Cronbach alpha for this scale was .64 for this sample.

A 10-item Counselling Content and Context Scale (see Table 2). These items were developed together with the HIV counselling trainer and other HIV experts and the WHO counselling and testing manual (WHO 1990: 3-10). The items were taken to three HIV counselling nurses who did not form part of the final sample who confirmed that all items were included in their routine counselling. Response options were yes or no. The Cronbach alpha for counselling content and context was .66 for this sample.

A 10-item Counselling Satisfaction Scale (see Table 3). These items were also developed together with the HIV counselling trainer and other HIV experts and the WHO counselling and testing manual (WHO 1990: 20-5). Response options were from $1=$ strongly agree to $5=$ strongly disagree. The Cronbach alpha for the satisfaction scale was .66 for this sample.

A Self-Disclosure Scale by Petrak, Doyle, Smith, Skinner and Hedge (2001: 69), examining the factors that are associated with self-disclosure of HIV serostatus to significant others was used. The scale consisted of four items. Participants were asked to identify up to 10 most important people in their lives and their relationship to them. They were also asked "does this person know that you are HIV positive?" "Followed by an open-ended question enquiring into the main reason for disclosing or not disclosing their HIV diagnosis."

A 6-item Social Support Scale by Sarason, Levine, Basham and Sarason (1983: 127). The scale has six items which entail different situations in which one can need support and participants were asked to list all individuals who provided them with support in the situation described and then subjects also rated their level of satisfaction with the support received. The level of satisfaction was rated on a six-point Likert scale from l=very satisfied to $6=$ very dissatisfied. The Cronbach alpha for the social support scale was .65 for this sample.

Behaviour Change questions included (1) "How many times in the past three weeks have you had vaginal sex without a condom", and (2) "How many times in the past three weeks have you had sex with a condom?" and both questions were followed by an open-ended question, Why?"

All questionnaires were translated from English to Northern Sotho and back translated according to scientific standard procedures.

\section{Data analysis}

Quantitative data were analysed using the SPSS package version 11.0. Descriptive statistics, student-t test, Pearson Chi-square and Pearson correlations were used. Qualitative data such as open-ended reasons for non-disclosure and disclosure of HIV were categorized with titles partially derived from previous work and agreed by coders (Petrak et al., 2001: 73). According to Miles and Hubermann (1994: 30.f.) agreement of . 70 and above indicate acceptable levels of agreement.

\section{Results}

Results are divided into (1) reasons for having an HIV test, (2) past sexual risk behaviour, (3) counselling content and context, (4) counselling satisfaction, (5) disclosure of HIV status, (6) sexual behaviour change, (7) HIV knowledge, and (8) social support.

\section{Table 1: Past sexual risk behaviour by gender}

\begin{tabular}{|c|c|c|c|}
\hline $\begin{array}{l}\text { Number of partners in the } \\
\text { past three years }\end{array}$ & $\begin{array}{l}\text { Male } \\
f(\%)\end{array}$ & $\begin{array}{l}\text { Female } \\
f(\%)\end{array}$ & $t$ \\
\hline 0 & $1(7.1)$ & $4(9.8)$ & \multirow{4}{*}{$5.51^{* * *}$} \\
\hline 1 & $2(14.3)$ & $23(56.1)$ & \\
\hline $2-3$ & $3(21.4)$ & $13(31.7)$ & \\
\hline \multirow[t]{2}{*}{$4+$} & $8(57)$ & $1(2.4)$ & \\
\hline & & & $X^{2}$ \\
\hline Condom use in past year & $1(7.1)$ & $12(30)$ & 2.96 \\
\hline Ever had STD & $8(57)$ & $13(32)$ & 2.86 \\
\hline
\end{tabular}

${ }^{* * *} \mathrm{p}<.001,{ }^{* *} \mathrm{p}<.01,{ }^{*} \mathrm{p}<.05$ 
Table 2: Counselling content and context in affirmative responses by frequency (percent)

\begin{tabular}{|l|c|}
\hline & $f(\%)$ \\
\hline 1. Counselling session was held in a private place & $38(69.1)$ \\
\hline 2. Counsellor promised not to tell anyone & $42(76.4)$ \\
\hline 3. Counsellor allowed me to talk and ask questions & $52(94.5)$ \\
\hline 4. Counsellor told me to use condoms whenever I had sex & $47(85.5)$ \\
\hline 5. Counsellor told me I had the right not to tell anyone about my HIV status should I & $48(87.3)$ \\
\hline prove positive & $49(89.1)$ \\
\hline 6. Counsellor insisted on the use of condoms even if I am positive & $44(80.0)$ \\
\hline 8. Counsellor told me that if I test positive it does not mean I am going to die & $44(80.0)$ \\
\hline 9. Counsellor told me that if I test negative I am definitely not infected & $31(56.4)$ \\
\hline 10. Counsellor said whenever I need to talk to someone I should call her & $36(65.5)$ \\
\hline
\end{tabular}

\section{(1) Reasons for having an HIV test}

The participants who were interviewed described a combination of factors that influenced their decision to be tested for HIV. The factors that motivated them differed markedly between men and women. Men came for testing mainly because of their own illness whereas women came because of illness of partner, and own illness and other factors including rape, pregnancy and risk behaviour. Illness (71\%) came out as the predominant factor that influenced testing, followed by rape (13\%), partner illness $(9 \%)$, pregnancy $(4 \%)$, and lastly risk behaviour (4\%). Different kinds of illnesses were mentioned but the predominantly mentioned ones were vaginal and mouth thrush followed by flu and coughing.

\section{Own IIIness}

Own illness was mentioned as a motivating factor for people who went for testing especially if the illness was recurring or a person had been ill for some time. This made them aware of their risk, especially if they believed that what they are suffering from had symptoms related to HIV. Participants said:

"I have been ill for a long time, I have lost weight, my mouth has sores...all the symptoms of AIDS. People were even afraid of me and were talking behind my back, so I wanted to know for sure." (Male, 37 years)

"I decided to test because I had continuous flu and coughing. When I cough a very smelly phlegm will come out through the mouth and nose..." (Female, 34years)

\section{Rape}

The issue of rape is another reason that forced people especially women to do HIV tests.
"A man raped me, I was so ashamed of myself afterwards, and I could not tell anybody about it, I just suffered alone. After some months I realized that I might be infected with HIV... I went to the hospital and for the first time...I told the doctor, he then suggested that I do the tests." (Female, 18 years)

\section{Illness of partner}

Perception of personal susceptibility to HIV infection is the primary motivating factor which motivates people especially women to seek HIV testing. For many of them illness of partner raised their personal awareness of risk. This is evident from one participant who said:

"My partner has been very ill for a long time so he would not tell me what was wrong with him. Because of how he looked and that I am not his only wife I decided to come for testing." (Female, 38 years)

\section{The need to have a child}

The need to have a child or reproductive health problems made women to decide to have an HIV test. One woman put it this way: "I wanted a child and needed to know my HIV status before I fell pregnant." (Female, 30 years). The other one had this to say: "My partner left me because I could not get pregnant, so I came to hospital to ask whether I was able to fall pregnant or not so they were running all sorts of tests... and HIV was one of them." (Female, 24years)

\section{Risk behaviour}

Risk behaviour is one other reason that brings people to HIV testing. They will want to know if they have acquired the virus after engaging in risky behaviours. This is reflected in the following statement: "I wanted to know (if I am HIV positive) because I have slept with a guy I met at a 


\begin{tabular}{|l|l|l|l|}
\hline Items & \multicolumn{2}{l|}{ Gender } \\
\hline & Male & Female & \\
\cline { 2 - 4 } & $\mathrm{M}(\mathrm{SD})$ & $\mathrm{M}(\mathrm{SD})$ & $t$ \\
\hline 1. My counsellor seems competent and well trained & $1.5(.7)$ & $1.1(.3)$ & 2.98 \\
\hline 2. My counsellor was understanding and warm & $1.5(.5)$ & $1.5(.5)$ & .55 \\
\hline 3. My counsellor seemed to care about me & $1.5(.5)$ & $1.6(.5)$ & .51 \\
\hline 4. My counsellor explained things in words I could understand & $1.4(.5)$ & $1.3(.5)$ & .56 \\
\hline 5. My counsellor let me tell her everything I thought was important & $1.5(.7)$ & $1.4(.6)$ & .81 \\
\hline 6. I would not feel comfortable asking my counsellor questions & $2.1(.3)$ & $2.3(.8)$ & .96 \\
\hline 7. My counsellor has not explained my problems to me & $2.0(.0)$ & $2.1(.8)$ & .57 \\
\hline 8. My counsellor has had a complete understanding of things that \\
are bothering me & $2.1(.3)$ & $1.8(.5)$ & 1.91 \\
\hline 9. I have great deal of confidence in the counsellor who talked to me & $1.5(.5)$ & $1.4(.5)$ & .71 \\
\hline $\begin{array}{l}\text { 10. I am very satisfied with the services of the counsellor who have } \\
\text { given me HIV testing }\end{array}$ & $1.2(.4)$ & $1.1(.3)$ & .91 \\
\hline Total (range 10-50) & Mean (SD) & Mean (SD) & t \\
\cline { 2 - 5 } & $16.4(2.0)$ & $15.6(2.3)$ & 1.10 \\
\hline
\end{tabular}

party without using a condom." (Female, 21 years). A man put it this way: "My girlfriend came back from Swaziland ill; she told me that she might have HIV. I love her a lot so I looked after her until she got better. We started having sex together using a condom. Then she recovered completely until there was no trace of illness on her, so one night I got tempted to sleep with her without a condom, she looked so beautiful and healthy so I thought the doctors must have made a wrong diagnosis... and that was how I got it." (Male, 42 years).

\section{(2) Past sexual risk behaviour}

Table 1 shows past sexual risk behaviour.

Half of the men reported having four partners and above, whereas half of the women reported having one partner in the past three years. Men reported to have had more sex partners than women in the past three years. Considering condom use in the past year, more women $(30 \%)$ reported using condoms than men $(7.1 \%)$.

\section{(3) Counselling content and context}

Table 2 indicates counselling content and context evaluation.

Participants were asked whether or not the counsellor had addressed the items in Table 2. Most areas were adequately covered except for items 1,9 and 10 . One third of the participants did not believe that counselling was held in a private place, $50 \%$ of males and $41 \%$ of females did not know about the window period, and $50 \%$ of males and $30 \%$ of females indicated that they were not told to come back when they needed to talk (follow-up counselling). Chi-square showed no significant differences between males and females with regard to context and content of HIV counselling.

\section{(4) Counselling satisfaction}

Participants were asked how satisfied they were with the counselling services and the results indicate that they were generally all satisfied with counselling services. They're no significant gender differences (see Table 3 ).

Counselling content and context were found to be associated with counselling satisfaction $(r=.29, p<.05)$

\section{(5) Disclosure of HIV status}

From 47 participants at follow-up $30(63.8 \%)$ had not disclosed and $17(36.2 \%)$ had disclosed their HIV status to their partner (8), followed by mother (7) and other (2). Reasons for non-disclosure included fear of negative reactions, discrimination, context of disclosure, fear of violence, con- 
Table 4: Satisfaction with social support

cerns about confidentiality, and timing, and reasons for disclosure included social support, both partners had it, blame, and personal responsibility.

Reasons for
non-
disclosure
of HIV
status

\begin{tabular}{|l|l|l|l|l|l|l|}
\hline Item & Listen & Help & Depend & Be yourself & Appreciate & Console \\
\hline & $\mathrm{M}(\mathrm{SD})$ & $\mathrm{M}(\mathrm{SD})$ & $\mathrm{M}(\mathrm{SD})$ & $\mathrm{M}(\mathrm{SD})$ & $\mathrm{M}(\mathrm{SD})$ & $\mathrm{M}(\mathrm{SD})$ \\
\hline Parents & $5.4(.7)$ & $5.2(.7)$ & $5.2(.6)$ & $5.4(.5)$ & $5.2(.6)$ & $5.4(.7)$ \\
\hline Siblings & $5.0(.7)$ & $5.2(.8)$ & $5.0(.0)$ & $5.5(.7)$ & $5.0(1.0)$ & $5.0(.6)$ \\
\hline Family & $5.0(.7)$ & $4.8(.5)$ & $5.3(.6)$ & $4.7(.7)$ & $5.4(.6)$ & $5.0(.5)$ \\
\hline Professionals & $5.9(.3)$ & $5.0(.9)$ & $5.0(.8)$ & $5.6(.5)$ & $5.5(.7)$ & $5.5(.7)$ \\
\hline Friend/partner & $5.4(5.4)$ & $5.3(1.0)$ & $4.92(.8)$ & $5.1(.9)$ & $5.3(.8)$ & $5.7(.6)$ \\
\hline No one & $3.0(1.4)$ & $2.7(1.3)$ & $1.9(.3)$ & $2.5(.7)$ & $1.7(.5)$ & $2.1(.6)$ \\
\hline
\end{tabular}

Open-ended questions on reasons for disclosure of HIV status were asked. All participants provided a variety of reasons for disclosing or not disclosing their HIV status and these were as follows: $24 \%$ did not disclose because they were afraid of negative reactions such as abandonment from the recipient of disclosure; $12 \%$ were afraid of discrimination; another $12 \%$ were afraid of violence; $8 \%$ were concerned about the context in which they disclosed their HIV status, $4 \%$ were afraid that the information might not be held confidential, and lastly, $4 \%$ felt that they are not yet ready to disclose.

\section{Fear of negative reactions}

Fear of negative reactions from partners, family and friends influenced the participant's decision not to disclose their HIV status. Many of the women were afraid that if their partners were to find out about their HIV status, they would abandon them. One participant stated that:

"If I tell my partner he will think that I have been sleeping with other men and he will walk out on me."

Some women believed that their children would walk out on them or throw them out of the house if they were to know of their HIV status. This was because even though these women were not married; they were old and had secret affairs, which their children did not know anything about. One woman stated:

"What will my children think of me, I am an old woman, they did not even know I had someone I was sleeping with, so to learn that your mother is having this filthy virus will make them not respect me. It is so embarrassing. I think they will chase me away."

\section{Discrimination}

Another major factor regarding disclosure was fear of discrimination. Fear of discrimination was of particular concern when disclosure involved family and friends. They felt that they would be treated differently and people would be ashamed of being associated with them. The following statement indicates how the participant felt:

"I did not tell anybody because I am afraid that they will

not want me anymore, they will not want to be associated with me. They will treat me badly as if I will contaminate them, so it is better for them to find out when I am really dying so that I will not have to endure their scorn..."

\section{Context of disclosure}

Disclosure concerns varied somewhat according to the persons involved. Three major categories of individuals about whom participants voiced concerns were children, partners, and parents. Participants were concerned about how their disclosure would affect their children. They expressed the belief that children should be told but many had not yet disclosed because of the concern that children could be negatively affected. Two participants said:

"I could not tell my children because they are still young, they would not understand and this will devastate them. When they are older I might consider telling them."

"How do you begin telling your children that you have a disease that you got it through sex? It is difficult, I know I am going to die but I want to die with the respect my children have for me."

Participants also expressed unwillingness to disclose to their partners because of their inability to predict how they will react. A major concern was that disclosure to sex partners would result in an end to the relationship. One participant described it this way: "My husband will freak out and leave me, he will not even want to touch me, and I will be all alone"

Participants were also concerned about putting their families especially their parents through discrimination. Some of them felt that they had disappointed their parents by having this dreadful disease. One woman put it this way: "I am afraid that my mother will be disappointed and hurt and she will not be able to deal with this. Every time there is a funeral in our village there will be gossip that the person died of AIDS, I see how my mother reacts, she thinks young women of today go all out to look for AIDS so if she knew my condition, this will destroy her."

Other participants said they did not tell their family mem- 
bers about their HIV status because their families had high expectations from them so it would be like dashing all their dreams and aspirations. According to them, it would be better t $\rho$ die without the family knowing what killed them.

\section{Fear of violence}

Most women were afraid that if they told their partners that they were HIV positive they would abuse them physically or kill them. This is because they knew the violent nature of their relationships. This is reflected in the following statement: "I am afraid that if I tell my partner that I am having this virus, he will beat me... he is a violent man and he will think that I have slept with other men." The other woman put it this way: "If I tell my husband, he will definitely kill me, he will accuse me of all sorts of things or walk out on me and refuse to take care of our children, I cannot risk that."

\section{Concerns about confidentiality}

A major concern that was mentioned by participants was that the recipient of disclosure could not be trusted to keep the information in confidence. Loss of control of confidentiality represented potential exposure to discrimination. The following statement by a participant demonstrates this concern: "I am afraid that if I tell someone, they will tell others. I want it to be my own secret. If other people know they will treat me badly" Another woman put it this way: "People like talking too much, if you tell one she will go around telling others and at the end of the day, the community will be looking at you as if you are poison. Already people are suspicious because I have been ill for a long time, they are already speculating that I have AIDS, so I do not want to confirm their suspicions."

\section{Timing}

Some of the participants had the perception that the time was not appropriate due to either not feeling prepared or still being in good health. One participant said: "I am not prepared to share this with anyone at the moment, it is so overwhelming, I do not think they will understand." The other one said: "I am not ill at present, I do not show any signs, when I am really ill, I will tell them."

\section{Reasons for disclosure of HIV status}

For those who managed to disclose their HIV status they mentioned that they did so because they wanted support (18\%), or because they felt it their personal responsibility to do so $(8 \%)$, or because they already knew that the other partner had it $(4 \%)$ or they to blame their partner because they believed that he/she had brought them the virus $(6 \%)$.

\section{Support}

One of the given reasons for disclosure of HIV status was to generate support. Participants indicated that they could get support from partner, parent or priest. One woman put it this way: "I told my priest so that she can pray for me, as for my mother, I told her because I wanted her to buy food for me and my kids, my husband is too ill already, my mother was always telling me to stop being lazy and look for work since my peers are working." Those who told their partners had this to say: "I told my wife and children because I wanted their understanding and support to get through all this. I could not manage on my own. They were shocked at first but now they are very supportive of me, I did not want them to hear this from somebody else." Some said they told their parents because they could count on them for support and understanding and again they felt it was a heavy burden to carry on their own. One of the participants said: "I told my mother because this was a heavy load for me, I trusted her to keep this a secret and I know that I can talk to her about my problems because now she knows"

\section{Both partners had it}

Some participants disclosed their HIV status because both partners had it and they wanted themselves to be the only ones who knew. One participant said: "My husband tested positive before I could find out about my status, he was very ill and I suspected HIV because I suffered the way my husband suffered, so I took myself to testing and I found out that I was HIV positive." The other participant had this to say: "I took it from her, that is why I told her...she once told me that she was HIV positive, she was very ill in those days, I looked after her until she was well, we were using condoms whenever we had sex, then she looked very healthy as if she was never ill, I fooled myself into believing that she did not have it any more, no one who looked the way she did could have HIV, so one day I slept with her without a condom, after a long time I started getting ill, that is when I discovered the truth........I had HIV also."

\section{Blame}

One participant indicated that she told the partner because she blamed him for the situation she found herself in: "I told him because I am sure I got it from him, I have never slept around in my life, I was faithful to him. he had been ill for a long time and refused to go for the tests because he already knew because all the signs were there...he was very unfaithful before he got this illness."

\section{Personal responsibility}

Some participants felt that it was their personal responsibility to inform others so as not to infect them whereas others stated that the partner had the right to know. Others disclosed their HIV status because they felt that they could not let other people take care of them without knowing what they are suffering from. One woman put it this way: "I told my husband because I wanted him to know, I cannot live with this secret or lie to him forever... fortunately he stood by me."

\section{(6) Sexual behaviour change}

Twenty-three participants $(48.9 \%)$ indicated that they had had sex without condoms in the past three weeks. Eight (17\%) of participants reported having had sex with condoms. They indicated that they did so because they wanted to protect their partners from infection or wanted to protect themselves from re-infection. "I do not want to infect my partner every time I have sex, that is why we use condoms." Sixteen $(34 \%)$ had not had sex in the past three weeks.

Reasons for not using condoms included losing a relationship, fear of violence, never have used condoms and not 
ready to disclose their HIV status, and reasons for not having sex included partner left, avoiding it, illness and ended relationship.

\section{Losing a relationship}

Some of the women who had sex without a condom did it out of fear of losing a relationship. One woman put it this way: "We have not had sex in the past three weeks because I was ill, but we do have sex and would not want my partner to know because he would treat me differently or go out of my life. If I become seriously ill like now he waits until I get better before we can have sex, so if I tell him to use a condom because I have HIV he will go forever out of my life." The other woman said, "I am afraid of telling him to use condoms because he will want to know why, if I tell him I will be on my own."

\section{Fear of violence}

Many women who had sex without a condom gave fear of violence as their reason for not having sex with a condom. They had the intention of disclosing but were afraid. One woman had this to say: "I want to tell my husband about my HIV status but I could not stand his abuse and again he may leave me, so who will look after the children and me. I once asked him to use condoms and he accused me of sleeping with other men and nearly beat the life out of me." Another woman put it this way: "My husband is a very abusive man, he sleeps around and does not want to use protection even though he knows that I know that he sleeps around. If I as much as breathe a word about it, he will beat me."

\section{Never used condoms}

Many participants reported that they had sex without condoms because they have never used them before and suggesting them late in a relationship would raise suspicions. "Since we were married we have never used condoms, and I cannot start it now...........it will raise suspicions."

\section{Not ready to disclose}

Some of the women indicated that they were having sex without condoms because they were not ready to disclose their HIV status. One participant said: "I am not yet ready to confess that I have this deadly virus so it is still my secret. If out of the blue I introduce condoms things will be difficult at home"

\section{Partner left}

Some of the participants indicated that they had never had sex in the past because their partners had left them. "I have never had sex since I knew my HIV status because the man I was with walked out on me. We had a short term relationship and now he has gone away." Another one said: "I have never had sex ever since I started being sick, I do not have a steady partner, the one I was involved with was married so since I have become ill he has disappeared."

\section{Avoiding it}

Others had just been avoiding sex by giving excuses to their partners. One participants said: "I have never had sex since I discovered my HIV status, I could not bear it since I know that it is him who got me infected in the first place, I do not want to tell him my status but every time he wants to have sex, I find an excuse not to."

\section{IIIness}

Illness is one other factor that made people not to have sex in the last three weeks. "My partner is so sick, he could not do it even if he wanted to."

\section{Ended relationship}

Some of the participants had ended their relationships since discovering that they were infected so they had not been having sex. This indicates that they were very disillusioned about relationships. "Since I found out that I was HIV positive, I ended the relationship. So since then I have never had sex again, I do not think any man will ever touch me again"

\section{(7) HIV knowledge}

HIV general knowledge was at first assessment $8.0(\mathrm{SD}=1.5)$ (range 0-9) and at follow-up 8.6 $(\mathrm{SD}=1.8)$, which is adequate. However, HIV transmission knowledge dropped from 43.2 $(\mathrm{SD}=6.9)$ at first assessment to $31.5(\mathrm{SD}=2.2)$ at follow-up $(t=11.30, p<.001)$. Wrong transmission modes were emphasised at follow-up such as eating in restaurant where the cook has AIDS, sharing plates/forks/glasses with an infected person and working near someone who has AIDS.

\section{(8) Social support}

Satisfaction with social support was calculated using the means and standard deviation. It was found that people who had someone to give him or her support were satisfied and those who did not have anybody to give them support were dissatisfied. Professionals were rated highly in terms of support, followed by parents, family, siblings, and lastly friend/partner. Those who indicated that they had no one to support them reported dissatisfaction with lack of support (see Table 4).

Social support was found to be significantly related to disclosure of HIV status ( $\mathrm{t}=2.14, \mathrm{p}<.001)$, while counselling context and content $(\mathrm{t}=.17$, ns) and counselling satisfaction $(t=-.72, n s)$ was not related with HIV disclosure.

\section{Discussion}

\section{Reasons for seeking HIV testing}

Illness, especially own illness and illness of partner, stood out as the most important reason for seeking counselling and testing for HIV. Other factors such as rape, the need to have child and risk behaviour also played a role. Illness is seen as raising one's perception of risk; this is consistent with Maman et al. (2000: 597) study. Sliep et al. (2001) also found among patients in rural Malawi that they only get HIV tested on medical indication.

\section{HIV general and transmission knowledge}

At first assessment general HIV and transmission knowledge were high but at follow-up general knowledge in- 
creased even more whereas transmission knowledge decreased. As far as transmission knowledge is concerned, wrong transmission modes were emphasised. This may be because people with HIV tend to feel toxic, as if they are dangerous to other people who get close to them (Hoffman, 1991 : 497). Peltzer, Hira, Wadhawan and Kamanga (1989: 168) also found considerable denial and misconceptions about HIV at subsequent counselling sessions among Zambian patients.

\section{Counselling context, content and satisfaction}

The results of this study indicate that counsellors had nearly managed to cover important aspects of HIV counselling and testing, as almost all the items had been rated high. One third of the participants indicated that the place was not private, which means people were coming in when the sessions were on. Fifty percent of males and $41 \%$ of females did not know about the window period and the same percentage of males and $30 \%$ percent of females were not told about follow up counselling. A one-time post-test counselling session may be inadequate for some who need time to weight the costs and benefits of disclosure and to develop a disclosure plan (Maman et al., 2001: 601). Partner notification and post-test support services need to be improved.

Participants in this study reported high levels of satisfaction with the counselling services. It is nevertheless difficult to develop an objective measure of client satisfaction. Research indicates that client satisfaction following counselling has always been reported as being high. This may be in part because clients do not want to upset their health providers or feel that criticizing a service would jeopardize their future care (UNAIDS, 2001: 43f.).

\section{Disclosure of HIV status}

From a sample of 47 at follow-up, only $36 \%$ had disclosed their HIV status whereas $64 \%$ did not do so, which are conform to findings from other studies (Moneyham et al., 1996: 215 ; Stein et al., 1998: 255). UNAIDS (2001:22f.) notes that most people will disclose to someone with time in developing countries (24-79\%).

Major reason for not disclosing of their HIV status were in this study being afraid of negative reactions such as abandonment from the recipient of disclosure, fear of discrimination, fear of violence, concerns about confidentiality and not yet ready. Petrak et al. (2001: 72) found in the UK similar reasons for non-disclosure, namely protecting others from distress, discrimination, stigma, concerns about confidentiality, and timing.

Major reasons for disclosure were in this study wanting support, felt personally responsible, knew or believed in HIV positive status of partner. Moneyham et al. (1996: 213), Petrak et al. (2001: 73) and Stein et al. (1998: 256) also found similar reasons for self-disclosure, namely desire for support, breach of confidentiality, personal responsibility, and was not their choice and/or emerged in the context of illness.

In this study social support was found to be significantly related to disclosure of HIV status, which conforms with findings from other studies (Hays et al., 1992: 463)

However, this study also found that counselling context and content and counselling satisfaction were not related with HIV disclosure. This may indicate that counselling needs to be improved regarding partner notification.

\section{Sexual behaviour change}

In the present study half of the participants indicated that they had had sex without condoms in the past three weeks. This is true for most women who reported fear of violence and abandonment among other things as factors that prevented them from engaging in safer sex practices. This can be attributed to the fact that women are often unable to discuss safer sex with their partners following counselling and testing because of gender imbalances in sexual decision-making. In an VCT outcomes study in Uganda it was found that before testing, $10 \%$ consistently used condoms and 6 months after testing, $89 \%$ consistent condom use with steady and $100 \%$ with non-steady partners. HIV-men with non-steady partners increased consistent condom use from $34 \%$ to $93 \%$, and with steady partners from $16 \%$ to $38 \%$. HIV-women increased condom use with non-steady partners from $14 \%$ to $94 \%$, and with steady partners from $15 \%$ to $34 \%$ (UNAIDS, 2001: 34-6). Condom use after five months of VCT was in the DRC 35\% (Kamenga et al., 1991: 63).

One of the main aims for counselling and testing is to reduce HIV transmission by encouraging changes in sexual behaviour following testing. It is therefore important to be able to share HIV status with one's sexual partner in order to make appropriate changes in sexual behaviour. Even though counselling and testing have been said to enable many people to change their sexual behaviour, not all are able to do so.

\section{Social support}

Social support results of the present study are consistent with the general finding that social support may be instrumental in adjusting to a variety of chronic illnesses, in this case, being HIV positive. Social support seems to go hand in hand with disclosure of HIV status. The results of the present study indicate that people who had disclosed their HIV status had more social support than those who had not disclosed the status. Hoffman (1991: 470) maintains that support groups are the single most important and effective intervention for many HIV infected individuals. They are said to help PWA's normalize the effects of this life crisis, recognize fear as a common reaction, provide a place to ventilate emotional reactions and gain a feeling of control (Cawyer \& Smith-Dupre, 1995: 243). They conducted an ethnographic study which described the supportive episodes that occurred during a meeting of HIV/AIDS support group for health care providers, family members, friends and lovers of PWAs, individuals who have lost their loved ones to the disease and those who were seropositive or infected with AIDS. They found that the support group did help people express frustrations and other emotions, prepare for complications of the disease and death, and mobilize their energies toward social change. They concluded that communicative episodes perform functions integral to 
the group's success in dealing with issues surrounding HIV/AIDS.

Many studies such as by Catania, Turner, Choi and Coates (1992: 999), Hays, Chauncey and Tobey (1990: 743), and Mfusi and Mahebeer (2000: 122) indicates lovers, friends, and family are the sources of support that HIV positive individuals turn to in times of distress. This is not true where the present study is concerned. The fact that most participants tended to mention professionals, in this case nurse-counsellors, more often as sources of support suggests that nurse-counsellors are the important sources of social support to which HIV positive individuals turn in times of stress. Individuals with poor support systems are at much greater risk of poor adjustment and inadequate coping styles as the present study has indicated.

\section{Limitations of the study}

This study comprised a very small sample, mainly consisting of women, generalization of the findings to all HIV positive people in the Limpopo Province can be misleading. HIV counselling was not observed or recorded, which makes it difficult to evaluate the counselling process itself. Further, patients need to be followed-up longer, i.e. after a year and 2 years, so as to evaluate sexual behaviour change.

\section{Recommendations/}

\section{Implications of the present findings for VCT in a hospital setting}

- The trainers of HIV counsellors should be trained on behaviour change counselling.

- They should also have training on disclosure counselling.

- $\quad$ There should be on-going counselling for clients who came for post-test counselling (clients should be encouraged to come back for counselling with incentives).

- If it is not possible for clients to come back for follow-up counselling there should be a special team in place who can do home visits.

- Counselling should be offered for families and partners of victims after disclosure has been done.

- $\quad$ There should be support groups in the communities so that even those who do not have money to travel to town can benefit from the group.

\section{Conclusion}

The results indicated that the participants have general knowledge of HIV but the transmission knowledge deteriorated with the progression of the disease, the reason being that they were emphasising wrong transmission modes. They also indicated satisfaction with counselling and that the context and content of counselling sessions that the counsellors used were in accordance with WHO guide- lines; and patients indicated that they were advised on those issues.

However, it was found out that it is difficult to initiate changes in sexual behaviour without sharing HIV test results with sexual partners/partner and this makes it difficult for one to get much needed social support to cope with the illness. The main reasons for lack of behaviour change were that many women were afraid of violence, and abandonment, and so they did not have the courage to negotiate safer sex practices. All this was brought about by the fact that they had not disclosed their HIV serostatus to their partners. Fear of negative reactions from family members, stigma, violence, and abandonment were the factors that were reported to work against disclosure of HIV serostatus.

\section{Acknowledgements}

Financial support by the National Research Foundation in South Africa is hereby acknowledged. Further we thank $\mathrm{H}$. Smith for the input in the HIV counselling evaluation measures.

\section{References}

ALLEN,S; TICE,J; VAN DE PERRE, P;SERUFILIRA, A; HUDES, E; NSENGUMUREYI, F; BOGAERTS, J; LINDAN, C \& HULLEY,S 1992: Effect of sero-testing with counselling on condom use and sero-conversion among HIV discordant couples in Africa. British Medical Journal. 304: 1605-1609.

CAMPBELL,C.H; MARUM, M.E; ALWANO-EDYEGU, M; DILLON, B. A; MOORE, M \& GUMISIRIZA, E. 1997: The Role of HIV Counselling and Testing in the Developing World. AIDS Education and Prevention. 9, Supplement B: $92-104$.

CAREY, MP \& SCHRODER KE. 2002: Development and psychometric evaluation of the brief HIV Knowledge Questionnaire. AIDS Education and Prevention, 14(2): 172-182.

CATANIA,J; TURNER, H; CHOI,K.H \& COATES, T. 1992: Coping with death anxiety: Help-seeking and social support among gay men with various HIV diagnoses. AIDS. 6: 999-1005.

CAWYER, C. S \& SMITH-DUPRE, A. 1995: Communicating social support: Identifying supportive episodes in an HIV/AIDS support group. Communication Quarterly, 43: 243-258.

CENTERSFOR DISEASE CONTROL. REVISEDGUIDELINES FOR HIV COUNSELLING, TESTING, AND REFERAL: MMWR.2001,50(RR19), 1-58.

CENTERS FOR DISEASE CONTROL. 1995: Evaluating CDC-funded health department. HIV prevention programs. Volume 1: guidance. Atlanta, GA: US Department of Health and Human Services, CDC, 1999.

DERLEGA, V. J \& BARBEE, A. P. 1998: HIV \& Social 
Interaction. London: Sage publications.

DUFFY, K. G \& WONG, F. Y. 1996: Community Psychology. London: Allyn \& Bacon.

GRINSTEAD, O. A. 1997: HIV counselling for behaviour change. AIDS Education and Prevention. 9(2): 125-132.

HAMMOND, E. 1987: Race, sex, AIDS: The construction of "other." Radical America. 20 (6): 28-36.

HAYS, R. B; CHAUNCEY, S \& TOBEY, L. A. 1990: The social support networks of gay men with AIDS. Journal of Community Psvchology. 18: 743-755.

HAYS, R. B; TURNER, H. A \& COATES, T.J. 1992: Social support: HIV symptoms and depression among gay men. Journal of Consulting Clinical Psvchology. 60: 463-469.

HOFFMAN, M. A. 1991: Counselling the HIV infected client: A psychological assessment and intervention. Counselling Psychologist. 19: 467-542.

HOLTGRAVE, D. R; REISER, W. J \& DIFRANCEISCO, W. 1997: The evaluation of HIV counselling and testing services: making the most of limited resources. AIDS Education and Prevention, 9(3 suppl): 105-118.

KAMB, M. L; FISHBEIN, M \& DOUGLAS, J.MJR. 1998: Efficacy of risk-reduction counselling to prevent human immunodeficiency virus and sexually transmitted diseases: a randomized controlled trial. Journal of American Medical Association. 280: 1161-1167.

KAMB, M.L; DILLON, B. A; FISHBEIN, M; WIILS, K. L \& THE PROJECT RESPECT STUDY GROUP. 1996: Quatity assurance of HIV prevention counselling in a multicenter randomized trial. Public Health Reports. 111(suppl 1):99-107.

KAMENGA, M; RYDER, R. W; JINGU, M; MBUYI, N; BEHETS, F; BROWN, C \& HEYWARD, W. L. 1991: Evidence of marked sexual behaviour change associated with low HIV-I seroconversion in 149 married couples with discordant HIV-1 serostatus: Experience at an HIV counselling center in Zaire. AIDS. 5: 61-67.

KARIM, Q 1995: Reducing the stigma of HIV infection among South African sex workers: socio-economic and gender barriers. American Journal of Public Health. 85 (11): 1521-1525.

KLINE, A \& VAN LANDINGHAM, M. 1994: HIV-infected women and sexual risk-reduction: the relevance of existing models of behaviour change. AIDS Education and Prevention. 6: 390-402.

LANE, J. D \& WEGNER, D. M. 1995: The cognitive consequences of secrecy. Journal of Personality and Social Psvchologv. 69: 237-253.
MACNEIL,J.M; MBERESERO,F \& KILONZO, G. 1999: Is care and support associated with preventive behaviour among people with HIV. AIDS Care. 11 (5): 537-546.

MAMAN,S; MBWAMBO, J; HOGAN, N. M; KILONZO, G. P \& SWEAT, M. 2000: Women's barriers to HIV-1 testing and disclosure: challenges for HIV-1 voluntary counselling and testing. AIDS Care. 13 (5): 595-603.

MARKS, G; RICHARDSON, J. L \& MALDONADO, N. 1991: Self-disclosure of HIV Infection to Sexual Partners. American Journal of Public Health. 81 (10): 1321-1322.

MARKS, G; BUNDEK, N.I; RICHARDSON, J. L; RUIZ, M. S; MOLDONADO, N \& MASON, H. R. C. 1992: Selfdisclosure of HIV infection: Preliminary results from the sample of Hispanic men. Health Psychology. 11 (5): 300306.

MEURSING, K \& SIBINDI, F. 1995: Condoms, family planning and living with HIV in Zimbabwe. Reproductive Health Matters. 5: 56-62.

MFUSI, S. K \& MAHABEER, M. 2000: Psychosocial adjustment of pregnant women infected with HIV/AIDS in South Africa. Journal of Psvchology in Africa. 10 (2): 122 145.

MILES, M \& HUBERMAN, A 1994: Qualitative data analysis. London: Sage.

MONEYHAM, L; SEALS, B; DEMI, A; SOWELL, R; COHEN, L \& GUILLORY, J. 1996: Experiences of Disclosure in Women Infected with HIV. Health Care for Women International. 17: 209-221.

MÜLLER, O; SARANGBIN, S; RUXRUNGTHAM, K; SITTITRAI, W \& PHANUPHAK, P. 1995: Sexual risk behaviour reduction associated with voluntary HIV counselling and testing in HIV infected patients in Thailand. AIDS Care, 7(5): 567-572.

PELTZER, K:HIRA.S.K; WADHAWAN,D \& KAMANGA, J.1989. Psychosocial counselling of patients infected with HIV in Lusaka. Zambia. Tropical Doctor. 19: 164-168.

PETRAK, J. A; DOYLE, A; SMITH, A; SKINNER, C \& HEDGE, B. 2001: Factors associated with self-disclosure of HIV serostatus to significant others. British Journal of Health Psvchology. 6: 69-79.

PIERCE, G. R ; SARASON, B. R \& SARASON, I. G. 1990: Intergrating social support perspective: working models, personal relationships, and situational factors. In S. Duck and R. C. Silver (eds), Personal Relationships and Social Support (p. 173-189), London: Sage.

REMIEN, R. H; RABKIN, J. G; WILLIAMS, J. B \& KATOFF, L. 1992: Coping strategies and health beliefs of AIDS longterm survivors. Psychology and Health. 6: 335345. 
SANGIWA, M. G; VAN DESTRATEN, A; GRINSTEAD, O. A \& VCT STUDY GROUP. 2000: Client's Perspective of the Role of Voluntary Counselling and Testing in HIV/ AIDS Prevention and Care in Dar Es Salaam, Tanzania: The Voluntary Counselling and Testing Efficacy Study. AIDS and Behaviour. 4(1): 35-48.

SARASON, I. G; LEVINE, H. M; BASHAM, R.B \& SARASON, B. R. 1983:Assessing Social Support: The Social Support Questionnaire. Journal of Personality and Social Psychology. 44 (1): 127-139.

SLIEP,Y; POGGENPOEL M.G \& MEINER, A 2001: The experience of HIV reactive patients in rural Malawi: Part I. Curationis. 24(3): 56-65.

STEIN, M. D; FREEDBERG, K. A; SULLIVAN, L. M; SAVETSKY, J; LEVENSON, S. M; HINGSON, R \& SAMET, J. H. 1998: Sexual Ethics: Disclosure of HIV-Positive Status to Partners. Archives of Internal Medicine. 158: 253-257.

TEMMERMAN, M; NDINYA-ACHOLA,J; AMBANI,J \& PIOT, P. 1995: The right to know HIV-test results. Lancet. $345: 969-970$.

UNAIDS. 2001: The impact of voluntary counselling and Testing: A global review of the benefits and challenges.

VAN DER STRATEN, A. 1995: Couple communication, sexual coercion and HIV risk reduction In Kigali, Rwanda. AIDS, $9(8)$ : 935-944.

WEINHARDT, L.S; CAREY, M . P ; JOHNSON, B .T \& BICKHAM, N. L. 1999: Effects of HIV Counselling and Testing on Sexual Risk Behaviour: A Meta-Analytic Review of Published Research, 1985-1997. American Journal of Public Health. 89 (9): 1397-1405.

WHO 1990: Guidelines for Counselling about HIV infection and disease: Geneva: WHO

Worth, D \& Rodriquez, R. 1987: Latina Women and AIDS. Siecus Reports. 15 (3): 5-7. 